\title{
Постановка метода тестирования активности системы gRNA/Cas9 в клетках эпидермиса картофеля
}

\author{
С.В. Герасимова*, А.А. Егорова, Ю.В. Сидорчук, А.В. Кочетов \\ ФИЦ Институт цитологии и генетики СО РАН, Новосибирск, Россия \\ *e-mail: gerson@bionet.nsc.ru
}

Метод редактирования генома на основе системы CRISPR/Cas позволяет модифицировать признаки картофеля и получать новые генотипы за относительно короткое время. Однако картофель является сложной культурой для генетической трансформации и требует исключительно вегетативного размножения, что осложняет генно-инженерные работы и порождает необходимость тщательной оптимизации методов для каждой задачи. В частности, при планировании эксперимента по геномному редактированию картофеля желательно провести предварительное тестирование активности РНК-направленной нуклеазы in vivo, и только после этого приступать к масштабному эксперименту. Удобным средством оценки эффективности системы модификации генома является метод восстановления активности генарепортера [1]. Он основан на системе трех генетических векторов: (1) контрольный вектор, несущий репортерный ген mCherry; (2) целевой вектор pTARGET, несущий нарушенный репортерный ген YFP со встроенным целевым сайтом и смещенной рамкой считывания; (3) вектор pRGEN, несущий систему РНК-направленного мутагенеза (gRNA, Cas9). При помощи биобаллистики все три вектора вносятся в клетку, и если Cas9 и gRNA функциональны, то они будут проявлять активность в отношении сайта, встроенного в последовательность ҮFР, и вызывать в нем мутации. С некоторой вероятностью рамка считывания YFP восстанавливается, и при воздействии соответствующего излучения появляется сигнал флуоресценции при длине волны 527 нм (желтый цвет). Относительное количество клеток, экспрессирующих YFP, к общему числу трансформированных клеток служит показателем активности каждой gRNA. Этот метод был описан для ячменя и табака, но до сих пор не был опробован на клетках картофеля. На основе векторов, описанных в [1] и [2], были сконструированы два вектора: pTARGET, несущий участок, идентичный участку генома картофеля, и pRGEN, несущий гены нуклеазы Cas9 и gRNA. Данная система векторов вместе с контрольным вектором была введена путем биобаллистики в клетки эпидермиса табака (Nicotiana benthamiana) и картофеля (Solanum tuberosum), методом конфокальной флуоресцентной микроскопии был проведен анализ количества успешно трансформированных клеток, и клеток, в которых отмечена экспрессия YFP. Показано, что на табаке и на картофеле метод работает с одинаковой эффективностью. В обоих случаях сигнал ҮFР появлялся с частотой примерно 25 \%.

Bblвoд: впервые поставлен метод тестирования системы редактирования генома картофеля in vivo при помощи восстановления активности репортера; показано, что данный метод обладает достаточной эффективностью для оптимизации экспериментов по модификации генома картофеля.

Благодарности: Работа поддержана грантом РНФ № 16-16-04073. Авторы благодарны ЦКП микроскопического анализа биологических объектов СО РАН (http://www.bionet. nsc.ru/microscopy/) за предоставленное оборудование.

Список литературь

1. Budhagatapalli N. et al. (2016) Plant Methods. BioMed Central. 12(1):1.

2. Schedel S. et al. (2017) Front. Plant Sci. 7(1):1. 